\title{
Entrepreneurial learning in extra-curricular start-up programs for students
}

\author{
Jasna Pocek and Diamanto Politis \\ Sten K. Johnson Centre for Entrepreneurship, Lund University, Lund, Sweden, and \\ Jonas Gabrielsson \\ School of Business, Innovation and Sustainability, Halmstad University, \\ Halmstad, Sweden
}

\section{Students' extra- curricular start- up programs}

Received 14 April 2020 Revised 17 November 2020 18 November 2020

Accepted 10 June 2021

\begin{abstract}
Purpose - This study focuses on extra-curricular start-up programs for students at higher educational institutions. It explores the social and situated learning experiences of students who participate in start-up programs, as well as how the processes and outcomes of entrepreneurial learning are potentially shaped by this context.

Design/methodology/approach - The study follows multiple cohorts of students who have participated in an extra-curricular start-up program managed by three collaborating universities in Greater Copenhagen. The data have been inductively analyzed using semi-structured interviews with students and project managers during and after the start-up program, complemented with project progress reports, observation notes and survey data.

Findings - The analysis generates a grounded, theoretically informed process model of entrepreneurial learning situated in extra-curricular start-up programs. The model depicts how the immersion, comprehension and co-participation in entrepreneurship as social practice subsequently enables students to expand knowledge structures and develop greater self-confidence in performing entrepreneurship. The model identifies three interconnected components that trigger entrepreneurial learning among students, which allow them to acquire two set of competencies: venture creation competencies and enterprising competencies.

Originality/value - The findings offer unique insights into how the social and relational environment influence and shape the learning experience of students, hence filling the research void on entrepreneurial learning in the situated context of extra-curricular enterprise activities. The findings also elucidate how individual learning experiences of students are potentially shaped by the immersion, comprehension and coparticipation in entrepreneurship as social practice.
\end{abstract}

Keywords Context, Entrepreneurial learning, Extra-curricular programs, Situated learning, Social learning Paper type Research paper

\section{Introduction}

Universities educate large volumes of students, some of whom will become tomorrow's entrepreneurs and innovators (Lindholm Dahlstrand and Berggren, 2010; Astebro et al., 2012). When universities are combined with entrepreneurially minded students, the two become a

\footnotetext{
(C) Jasna Pocek, Diamanto Politis and Jonas Gabrielsson. Published by Emerald Publishing Limited. This article is published under the Creative Commons Attribution (CC BY 4.0) licence. Anyone may reproduce, distribute, translate and create derivative works of this article (for both commercial and non-commercial purposes), subject to full attribution to the original publication and authors. The full terms of this licence may be seen at http://creativecommons.org/licences/by/4.0/legalcode

This paper forms part of a special section "Entrepreneurial Learning: The implications of Social Relationships and the Practice of Entrepreneurship", guest edited by Allan Macpherson, Lisa Anderson, Kiran Trehan and Dilani Jayawarna.

The authors acknowledge support from the EU project Nordic Entrepreneurship Hubs (NEH) which has been funded by Interreg Öresund-Kattegat-Skagerrak, European Regional Development Fund. The authors are also grateful for the helpful contributions from the participants at the USASBE 2020 Special Issue Workshop and the anonymous reviewers in the course of developing this work.
}

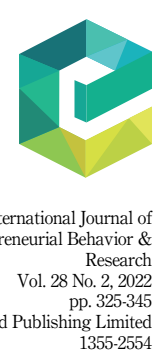

DOI 10.1108/IJEBR-04-2020-0206 
IJEBR

28,2

potent force that can boost the entrepreneurial capacity of the local region (Fetters et al., 2010). In this respect, many universities have incorporated dedicated spaces for entrepreneurship within their vicinities, such as makerspaces, mixed-use facilities, incubators and accelerators (Wright and Drori, 2018). Overall, these efforts are aimed at connecting students with academic research and supporting infrastructures that foster entrepreneurship, innovation and creativity, embedded in the overall mission of universities to engage in job and wealth creation in society (Youtie and Shapira, 2008; Foss and Gibson, 2015).

One type of entrepreneurial space increasingly offered by universities is university-led extra-curricular start-up programs, where students are invited to engage in enterpriseoriented training and networking in a supportive environment (Kolympiris and Klein, 2017). Interestingly, these programs provide a collective and organized learning context that differs compared to curricular activities (Williams Middleton et al., 2019), which is where most attention has been directed when it comes to studying entrepreneurial learning among students. Rather, these extra-curricular activities can be classified as non-formal entrepreneurship education organized outside the framework of the formal educational system (Levinsohn, 2015), yet within a structured and temporally compressed program aimed at increasing entrepreneurial intentions and behaviors of students.

Extra-curricular start-up programs for students provide a clear situated learning context outside the formal curriculum. Prior research highlights that student involvement in extracurricular activities such as membership in student clubs may foster entrepreneurial activity through social practice (e.g. Pittaway et al., 2015). However, there is up to date scarce research examining the situated context of extra-curricular start-up programs and their impact on student entrepreneurship (Morris et al., 2017; Shirokova et al., 2017; Preedy et al., 2020). Thus, we see considerable room for intensified scholarly inquiry that can provide research-based insights into the dynamics of entrepreneurial learning in extra-curricular start-up programs for students.

Against the above, the purpose of the study is to advance the scholarly understanding of the social and situated experiences of students who participate in extra-curricular start-up programs, by exploring how processes and outcomes of learning are potentially shaped by this particular context. Theoretically, we conceptualize the entrepreneurial learning of students as a situated process occurring through participating and interacting among and through other people (Ardichvili, 2003; Taylor and Thorpe, 2004). Empirically, we follow four rounds of coordinated extra-curricular start-up programs managed by three collaborating universities in Denmark and Sweden. The analysis identifies a set of interconnected components that trigger and shape entrepreneurial learning processes and outcomes among the students. Moreover, the analysis pinpoints conditions that can impede or facilitate the entrepreneurial process as manifested in extra-curricular start-up programs. In this respect, our study provide theoretical and empirical insights into the social dimensions of entrepreneurial learning taking place outside the framework of the formal educational system (e.g. Jones et al., 2014a, b).

The rest of the paper is organized as follows. The next section presents the literature review, where we discuss the literature and research on the social dimension of entrepreneurial learning, with a particular focus on student entrepreneurship. Thereafter in the third section, we introduce the methodology, and the fourth section presents the empirical findings. In the fifth and final, section we discuss the findings and their implications for theory and research.

\section{Literature review}

Universities across the globe experience increasing pressure from an expanding range of stakeholders to provide entrepreneurial education as a way of enhancing students' entrepreneurial learning. While the bulk of research attention on entrepreneurial education has been on in-curricular activities (e.g. Hägg and Gabrielsson, 2020) it is widely acknowledged that extra-curricular entrepreneurship support plays a critical role for the exchange of new 
knowledge between universities and the private sector (Yusef,2008; Preedy and Jones, 2015) and for providing an organized space where students can practice and learn entrepreneurship in a supportive environment outside the classroom (Politis et al., 2019). Extra-curricular activities are distinct from in-curricular activities owing to their voluntary nature (Preedy et al., 2020), where such activities are perceived to complement in-curricular provision offered at universities. Alongside the growth of entrepreneurship programs prior studies recognize an increase in the provision of extra-curricular entrepreneurship support including activities such as business plan and elevator pitch competitions, speaker series, student incubators, networking events and student-led clubs with the aim to support students in developing entrepreneurial knowledge, skills and capabilities (e.g. Rae et al., 2012; Vanevenhoven and Drago, 2015).

The literature on the role of extra-curricular entrepreneurship support makes a distinction between student- and university-led enterprise activities (Pittaway et al., 2015; Preedy et al., 2020). Student-led enterprise activities come in many forms (e.g. Pittaway et al., 2010) but can generally be characterized as informal, non-accredited societies or clubs who seek to attract students interested in learning about enterprise and developing entrepreneurial competencies. University-led enterprise activities, which we focus on in this study, refers to the delivery of assistance and support provided by staff to students outside of the main curriculum but still within the formal structure of a university (Preedy and Jones, 2015). In this respect, the extra-curricular support led by universities are often connected to regional, national or supranational policy efforts where they typically are seen as important vehicles for promoting economic growth by producing entrepreneurial graduates. On the individual level, studies suggest that extra-curricular enterprising activities offer benefits to students in terms of opportunities to experiment with entrepreneurial practice (Pittaway et al., 2015) and to connect with peers (Cordea, 2014; Pittaway et al., 2015). However, the specific value extracurricular start-up programs offers in terms of supporting students' entrepreneurial learning is less explored within the literature (Preedy et al., 2020).

One way to approach and understand extra-curricular start-up programs as platforms for enhancing students' entrepreneurial learning is to conceptualize their engagement as a process of "co-participation" (e.g. Taylor and Thorpe, 2004; Pittaway et al., 2010). Entrepreneurial learning is to high extent experiential and "on-the-job" (Cope, 2005; Politis, 2005), which implies limited time for reflection and mutual engagement in joint experience with others. Consequently, many entrepreneurs tend to have limited learning opportunities as they are isolated with few team or board members to discuss their ideas, set levels of achievement to aspire for and share learning with (Jones et al., 2007). However, by participating and interacting among and through other like-minded people, students become embedded within an entrepreneurial community where their learning experience becomes an integral and inseparable process of social practice (Lave and Wenger, 1991; Kubberød and Pettersen, 2017).

Cognitivist and constructivist theories emphasize the critical influence of the social context where people learn from each other through observation and modeling of behavior (e.g. Bandura, 1977; Vygotsky, 1978; Wenger, 1998). In this respect, prior research has identified that entrepreneurs often learn from peers as they seek guidance and support from people whom they believe have superior understanding or ability (Taylor and Thorpe, 2004; Cope, 2005; Preedy and Jones, 2015; Politis et al., 2019). Another observation in literature is the importance of shared learning experiences when entrepreneurs partner together both formally and informally (Pittaway and Cope, 2007; Pittaway et al., 2020). Adding to this, Rae (2006) emphasizes social and personal emergence as critical components in entrepreneurial learning which encompass both students' perceptions of themselves as entrepreneurs as well as their perceptions of how others see them in this role. In all, these observations call for contextsensitive theorizing (e.g. Thomassen et al., 2019; Welter and Gartner, 2019) that addresses not only the acquisition of technical and business skills, but also the development of self- and social awareness (Gibb, 2002; Rae, 2006; Penaluna et al., 2012; Jones et al., 2014a, b).
Students' extracurricular startup programs

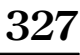


IJEBR

28,2

328

The social dimension of student entrepreneurship has been increasingly emphasized during recent years (Howort et al., 2012; Pittaways et al., 2015). Social networks plays an important role in embedding students to local networks as they provide exposure to financial, technical and advisory resources, but also to cultural norms and practices supportive of venture creation and risky entrepreneurial endeavors (Jack and Anderson, 2002; Spigel, 2017; Politis et al., 2019; Williams Middleton et al., 2019). Extra-curricular start-up programs can in this respect be conceived as social learning systems (e.g. Wenger, 1998) embedding students in a community of practice that connects them to networks and expose them to norms and relationships (Rae, 2002; Cope, 2005). At the same time, the importance of "realistic" environments becomes explicit as students are exposed to the entrepreneurial "way of life" (Gibb, 2002; Kwong et al., 2012) that enables them to develop or strengthen entrepreneurial competencies. Consequently, it seems reasonable to assume that the social situated context of extra-curricular start-up programs might play a central role in shaping students' learning and practice of entrepreneurship. Table 1 provides a summary of the key views and research opportunities that serve as the theoretical vantage point for our study.

Table 1.

Key message in the literature

\begin{tabular}{ll}
\hline Key message & Research opportunities \\
\hline $\begin{array}{l}\text { Extra-curricular start-up programs serves as a fertile } \\
\text { ground for students' learning and practice of }\end{array}$ & $\begin{array}{l}\text { There is limited theoretical knowledge on the specific } \\
\text { learning outcomes students acquire as a result of } \\
\text { entrepreneurship }\end{array}$ \\
$\begin{array}{l}\text { Extra-curricular start-up programs can be seen as } \\
\text { learning systems that expose students to "realistic" in extra-curricular start-up programs }\end{array}$ & $\begin{array}{l}\text { The literature is scarce on explaining how the } \\
\text { situated context of extra-curricular start-up }\end{array}$ \\
$\begin{array}{l}\text { environments and provide access to resources and } \\
\text { cultural norms supportive of venture creation }\end{array}$ & $\begin{array}{l}\text { programs shape entrepreneurial learning, and little is } \\
\text { known about the conditions that facilitate learning } \\
\text { processes }\end{array}$ \\
& $\begin{array}{l}\text { processes and learning outcomes in extra-curricular } \\
\text { start-up programs }\end{array}$ \\
&
\end{tabular}

To conclude, despite the widespread recognition of the value of university-led extracurricular entrepreneurship support for enhancing students' entrepreneurial learning there is only limited research on the subject. In particular, there has been limited literature examining the perceptions of students directly involved in delivery and receipt of extra-curricular startup programs. Taking this observation as our point of departure, in this study we seek to explore the social and situated learning experiences of students who participate in extracurricular start-up programs and its implications for theory and research on processes and outcomes of entrepreneurial learning. Guided by this overall purpose and inspired by the research opportunities identified in our literature review, we ask the following questions:

(1) What key learning outcomes do students experience when following extra-curricular start-up programs?

(2) How does the social and situated context of extra-curricular start-up programs shape students' learning processes and learning outcomes?

(3) What conditions impede or facilitate learning processes and learning outcomes in extra-curricular start-up programs?

\section{Methods}

Empirical setting

The empirical study is based on a regional cross border collaborative project between universities in Sweden and Denmark titled Nordic Entrepreneurship Hubs (NEH). The project 
was funded by the EU regional development fund Interreg Öresund-Kattegat-Skagerrak during 2017-2019 with the aim to strengthen the entrepreneurial ecosystem of Greater Copenhagen by providing extra-curricular start-up programs for students. The project involved a partnership between three higher education institutions: Copenhagen School of Design and Technology (KEA, Denmark), Lund University (LU, Sweden) and Technical University of Denmark (DTU, Denmark).

As part of the project, the three academic institutions have jointly organized extracurricular start-up programs to support student entrepreneurship by forming a network of hubs that combines entrepreneurial facilities and resources. The extra-curricular character of the program implies that completion was not graded or awarded credits as part of the official school syllabus. Thus, participation were on a voluntary basis and all program activities took place outside regular study hours during weekends.

There were in total four rounds of start-up programs organized at each of the three partner universities, resulting in twelve cohorts and 214 students in total. Each round started with a kickoff organized by the three academic institutions where all three student cohorts were jointly introduced to the program with access to facilities, expertise and business coaching. Thereafter followed scheduled activities which included individual meetings, group coaching and workshop activities. The topics for the workshops varied over the course of the project but included some of the following areas: business (goal-setting) meetings, business modeling, customer validation, graphic design, regulation, e-commerce and peer grading activities. The program also included "Hub tours" in the form of cross border visits to Danish and Swedish institutions. In addition, each of the three academic institutions organized some activities separately for their own cohort of students. The overall duration of the program was approximately ten weeks and it ended with a final pitching event organized as part of the cross border "Hub tour".

\section{Data collection}

The four rounds of start-up programs took place during the fall term 2017, the spring and fall terms 2018 and the spring term 2019. The research team was continuously observing and collecting data during this period as events were unfolding. The primary source of data consists of face-to-face interviews conducted with students and the project managers. Data were also collected from progress reports submitted to the funding agency as well as notes taken during observations in project meetings. In addition, a questionnaire survey was distributed to students to assess their belief in the ability to successfully launch an entrepreneurial venture. The multiple sources of data used in our analyses opened for a rich and contextual understanding of the research setting (Welter and Gartner, 2019) while at the same time making it possible to triangulate the interview data for enhanced validity and reliability (Jehn, 2009). An overall illustration of the empirical data used in the study is presented in Table 2. A more detailed breakdown of the data is presented in Table 3.

Semi-structured interviews. The primary source of data in our analysis consists of face-toface interviews with students and project managers. Before conducting the interviews we reviewed relevant research to build a semi-structured interview guide. The review enabled us to identify themes and topics where there is great potential for extending the existing literature (see Table 1) while at the same time allowing us to uncover unexpected issues and expand on topics led by the informants by engaging in "enforced ignorance" of the literature (e.g. Gioia et al., 2012).

A total of thirty-four semi-structured interviews were conducted over the project period; 21 interviews with students and 13 interviews with project managers. To open up for variations in the learning experience of students we selected informants based on selfassessments of the ability to successfully launch an entrepreneurial venture before and after
Students' extracurricular startup programs 
IJEBR

28,2

the program (see details on questionnaire in next section). We were also balancing the selection of informants with respect to gender. When approaching students we were careful in conducting interviews close to the learning experience, typically the first week following the completion of the start-up program. Project managers were selected as to include perspectives and experiences from all three project partners. All interviews were transcribed verbatim.

330

Table 2.

Empirical data

\begin{tabular}{lll}
\hline Source of data & Total number & Details \\
\hline Interviews & 34 interviews & $\begin{array}{l}\text { 34 interviews with 13 project managers and 21 students, conducted } \\
\text { during the 2017-2019 period }\end{array}$ \\
Surveys & $\begin{array}{l}\text { 8 survey } \\
\text { rounds }\end{array}$ & $\begin{array}{l}131 \text { respondents completed the matched surveys. Survey assessing } \\
\text { students' self-efficacy beliefs were conducted both in the beginning (pre- } \\
\text { test) and in the end (post-test) of the four rounds of start-up programs }\end{array}$ \\
$\begin{array}{l}\text { Reports } \\
\begin{array}{l}\text { Researchers' } \\
\text { notes }\end{array}\end{array}$ & $\begin{array}{l}\text { 12 status } \\
\text { meetings }\end{array}$ & $\begin{array}{l}\text { Project implementation progres reports } \\
\text { Observations from participation in status meetings }\end{array}$ \\
\hline
\end{tabular}

\begin{tabular}{|c|c|c|c|}
\hline $\begin{array}{l}\text { Time } \\
\text { period }\end{array}$ & Data source & Under investigation & Details \\
\hline \multirow[t]{4}{*}{ Fall 2017} & Interviews & $\begin{array}{l}\text { Project managers and } \\
\text { students }\end{array}$ & $\begin{array}{l}16 \text { interviews: } 5 \text { with project managers and } 11 \text { with } \\
\text { students }\end{array}$ \\
\hline & Surveys & Students & $\begin{array}{l}\text { Two rounds of self-efficacy survey - one in the } \\
\text { beginning and the other in the end of the program }\end{array}$ \\
\hline & Reports & $\begin{array}{l}\text { Progress of the } \\
\text { project }\end{array}$ & 1 progress reports sent to the $\mathrm{EU}$ \\
\hline & $\begin{array}{l}\text { Researcher } \\
\text { notes }\end{array}$ & $\begin{array}{l}\text { Progress of the } \\
\text { project }\end{array}$ & Notes from 3 status meetings \\
\hline \multirow[t]{4}{*}{$\begin{array}{l}\text { Spring } \\
2018\end{array}$} & Interviews & $\begin{array}{l}\text { Project managers and } \\
\text { students }\end{array}$ & $\begin{array}{l}9 \text { interviews: } 2 \text { with project managers and } 7 \text { with } \\
\text { students }\end{array}$ \\
\hline & Surveys & Students & $\begin{array}{l}\text { Two rounds of self-efficacy survey - one in the } \\
\text { beginning and the other in the end of the program. }\end{array}$ \\
\hline & Reports & $\begin{array}{l}\text { Progress of the } \\
\text { project }\end{array}$ & 1 progress reports sent to the $\mathrm{EU}$ \\
\hline & $\begin{array}{l}\text { Researcher } \\
\text { notes }\end{array}$ & $\begin{array}{l}\text { Progress of the } \\
\text { project }\end{array}$ & Notes from 3 status meetings \\
\hline \multirow[t]{4}{*}{ Fall 2018} & Interviews & $\begin{array}{l}\text { Project managers and } \\
\text { students }\end{array}$ & $\begin{array}{l}3 \text { interviews: } 2 \text { with project managers and } 1 \text { with a } \\
\text { student }\end{array}$ \\
\hline & Surveys & Students & $\begin{array}{l}\text { Two rounds of self-efficacy survey-one in the } \\
\text { beginning and the other in the end of the program }\end{array}$ \\
\hline & Reports & $\begin{array}{l}\text { Progress of the } \\
\text { project }\end{array}$ & 1 progress reports sent to the $\mathrm{EU}$ \\
\hline & $\begin{array}{l}\text { Researcher } \\
\text { notes }\end{array}$ & $\begin{array}{l}\text { Progress of the } \\
\text { project }\end{array}$ & Notes from 3 status meetings \\
\hline \multirow[t]{4}{*}{$\begin{array}{l}\text { Spring } \\
2019\end{array}$} & Interviews & $\begin{array}{l}\text { Project managers and } \\
\text { students }\end{array}$ & $\begin{array}{l}6 \text { interviews: } 4 \text { with project managers and } 2 \text { with } \\
\text { students }\end{array}$ \\
\hline & Surveys & Students & $\begin{array}{l}\text { Two rounds of self-efficacy survey - one in the } \\
\text { beginning and the other in the end of the program }\end{array}$ \\
\hline & Reports & $\begin{array}{l}\text { Progress of the } \\
\text { project }\end{array}$ & 1 progress reports sent to the $\mathrm{EU}$ \\
\hline & $\begin{array}{l}\text { Researcher } \\
\text { notes }\end{array}$ & $\begin{array}{l}\text { Progress of the } \\
\text { project }\end{array}$ & Notes from 3 status meetings \\
\hline
\end{tabular}

Table 3.

Data breakdown 
Progress reports and notes from observations. We complemented the interview data with progress reports. They were written on a bi-annual basis and were submitted to the institution monitoring the EU-funding of the project. The reports provided information about the progress of the project over the period, including accounts of activities undertaken and money spent. The information provided in the reports enabled us to access time-specific accounts of what project managers experienced was done right, what went wrong and what could be improved.

We also collected data by observing and taking notes from status meetings. The status meetings were organized regularly to share and discuss experiences across the project partners and shedding light on systemic issues or other potential causes of delay or failure that should be avoided or resolved. The project managers were also invited to separate meetings to discuss and reflect on the previous rounds of the start-up programs, the lessons learned and the improvements made as well as the improvements to be implemented. Notes were taken in all meetings to support our analysis.

Questionnaire survey. A questionnaire survey was designed to support the project in assessing a potential increase in students' belief in their capability to perform tasks and roles aimed at entrepreneurial outcomes. We used the 19-item multi-dimensional entrepreneurial self-efficacy measure developed by McGee et al. (2009) as it has been widely used in prior research to measure how individuals think and act entrepreneurially in the venture creation and development process (Newman et al., 2019). Moreover, the measure is suitable for both nascent and experienced entrepreneurs and with recent results providing support for the use of the scale outside the original population for which it was developed (Spagnoli et al., 2017).

The questionnaire was distributed twice to each of the twelve cohorts of students participating in the start-up program, with one pre-test survey in the beginning of the program period and a follow-up survey shortly after the program ended. Responding to the survey was voluntary, and we were able to collect 131 completed matched surveys out of 214 participating students which correspond to an effective response rate of $61.2 \%$. A series of non-response analyses did not reveal any statistically significant differences with respect to age, gender and cohort. Statistical analyses on the full sample using paired sample $t$-tests reveal a significant increase of entrepreneurial self-efficacy after completion of the start-up program, at $p=0.000^{* *}$. Additional $t$-tests breaking up the sample per partner institution and per program round showed robust results across both dimensions. The results from the various survey rounds were continually presented at status meetings, and they were also used for selecting students for the interviews to increase the chance of interviewing respondents with varying learning experiences (see section semi-structured interviews).

\section{Data analysis}

The interview transcriptions have been analyzed using the NVivo12 software. The data were read and coded in two levels following the approach taken in Pittaway et al. (2010). We engaged in a first level informant-centric analysis where the references were inductively coded into categories based on the accounts shared by the informants. Unclear categories were discussed and in a few cases reclassified. Remaining categories were then carefully reviewed and compared to identify emerging patterns. At this stage we also cross checked information collected from progress reports and notes from observations to add details and nuances to our inductive data structure.

The second level analysis involved the comparison of the coded references and their grouping based on theoretical concepts and tentative relationships. The existing literature was consulted multiple times to develop a grounded, yet theory-informed understanding aimed at extending the existing literature. The emerging patterns were finally organized to encompass the processes and outcomes of entrepreneurial learning in extra-curricular start-
Students' extracurricular startup programs 
IJEBR

28,2

up programs, and based on this theoretical structure we developed a process-focused model depicting theoretical concepts together with their relational dynamics. The next section reports the findings from the inductive analysis.

\section{Analysis and findings}

332

The inductive coding, as presented in Table 4, depicts three overall building blocks encompassing the processes and outcomes of entrepreneurial learning in extra-curricular start-up programs. These three building blocks include; (1) post-program learning containing key learning outcomes associated with students' situated experiences of participating in extra-curricular start-up programs, (2) components encompassing the social situated learning context of such programs and (3) conditional features influencing students' motivation to actively participate in the social learning culture, which indirectly influence the entrepreneurial learning outcomes.

The analysis identifies interview accounts associated with learning outcomes acquired through social situated experiences, which we label learning outcomes (39.3\% of the coded data). The learning outcomes can broadly be divided in two sub-categories where each category represents distinctive sets of competencies generated from the start-up program. The first sub-category refers to competencies associated with the performance of domainspecific tasks related to a new venture creation process. The second sub-category refers to a

\begin{tabular}{lll}
\hline Coding category & Reference counts & Percentage \\
\hline
\end{tabular}

Learning outcomes

$\begin{array}{lll}\text { Venture creation competencies } & 62 & 21.0 \%\end{array}$

$\begin{array}{lrr}\text { Enterprising competencies } & 54 & 18.3 \%\end{array}$

Total

116

Situated learning context

Enablers

Resource provision

Expansion of networks

Means-driven organizing

Community building

Total

Social learning culture

Community membership

Inspiration

Safety and comfort

Total

$\begin{array}{lr}43 & 14.6 \% \\ 16 & 5.4 \% \\ 16 & 5.4 \% \\ 11 & 3.7 \% \\ 86 & 29.2 \%\end{array}$

Learning processes

$\begin{array}{lrl}\text { Observation and communication } & 30 & 10.2 \%\end{array}$

Peer feedback 25

$8.5 \%$

Total

$18.7 \%$

Conditional features

Participatory conditions

Table 4.

Time allocation

Narrative coding and

Project proximity

19

10

$3.4 \%$

$3.1 \%$

9
38

$12.9 \%$

Total

Total references

$\begin{array}{rr}6 & 1.9 \% \\ 7 & 2.3 \% \\ 13 & 4.2 \% \\ 308 & 100.0 \%\end{array}$


broader set of competencies that are more generic in nature and associated with enterprising behavior and capabilities involving identify formation and ability to take an entrepreneurial role in a social setting, for example by showing a proactiveness, adaptability, or seeing opportunities and taking advantages of them.

Furthermore, the analysis suggests that students' learning experiences are embedded in three layers of components that together portray the situated learning context that is channeled through the extra-curricular start-up program. The first component, enablers $(29.2 \%$ of the coded data), refers to program-specific features that together provide the infrastructure and outer context of the start-up program. It is within the boundary of these agenda setting enablers where the second component, social learning culture $(12.9 \%$ of the coded data) can be created within the start-up program. Social learning culture refers to a collection of conventions and values that encourage students to share what they know and learn from their peers. This learning culture enables and opens up for reinforcing learning processes (18.6 \% of the coded data), which consist of practices and processes where students actively interact and engage with each other to learn and to grow.

Moreover, the analysis identifies conditional features influencing students' motivation to actively participate in the situated learning context, which we label participatory conditions ( $4.2 \%$ of the coded data). The conditional features consist of two sub-categories; time allocation and project proximity. The first sub-category, time allocation refers to invested time and energy students set aside to engage in the program as their commitments and responsibilities outside the extra-curricular start-up program are found to affect their degree of participation in the situated learning context. The second sub-category, project proximity refers to students' perceived closeness relative to others in the program with respect to stage of development in business idea as a conditional feature influencing students' motivation to take an active engagement in the social learning culture.

In the remainder of this section we will continue to discuss the findings from our analysis. First, with respect to the research questions identified in the end of the literature review we will center our discussion on the identified building blocks encompassing the social and situated experiences of students who participate in extra-curricular start-up program. The analysis will then continue with presenting an inductive, process-focused model depicting the dynamic relationships of entrepreneurial learning in extra-curricular start-up programs.

Question 1. What key learning outcomes do students experience when following extracurricular start-up programs?

With respect to question 1, our analysis identifies a range of developed or sharpened skills, abilities and attributes experienced by the students from their participation in the extracurricular start-up program. The emerging data structure highlights two main outcomes with respect to entrepreneurial learning: venture creation competencies and enterprising competencies.

\section{Venture creation competencies}

Venture creation competencies refer to the ability to use knowledge effectively and readily in the course of setting up a new venture. This includes executing and performing tasks such as opportunity creation, business modeling and business plan writing, marketing, communication with stakeholders, team building, financing and the mobilization of resources. In this respect, the competencies address issues related to building legitimacy and capabilities to overcome significant liabilities of newness in early stages of new venture creation. This set of competencies were discussed by one of the students in the following way:

\footnotetext{
...we have learnt to present our start-up in a good way, so that we can get attention from potential investors - we have improved a lot in this; knowing what to say... and what is not so important to say.
} 
IJEBR

28,2

Another student referred to venture creation competencies in the following way:

... I think we all learned a lot about team roles and how to work with our teams. We had a visitor, a lady who talked about the importance of team roles and the atmosphere in the team. I think that is really important.

Enterprising competencies

Enterprising competencies refer to the ability to show initiative and resourcefulness as means to make the most out of opportunities to improve processes and results. It includes the capability of being prepared to "think out of the box" and to take action regardless of context. It also includes executing and performing tasks such as innovative and original thinking, making prioritizations, communicating professionally and working independently. As such, these competencies are not exclusively connected to new venture creation settings, rather, they are more generic and person-centered including one's self-image which refers to knowledge about oneself and one's role as an entrepreneur in a surrounding community. One of the students described this set of competencies as follows:

I think I would say that I've learned more [about] what kind of person I am.

Another student explains enterprising competencies in terms of being adaptable and taking actions:

I learned that you cannot just have one idea and stick to that or think about it in a particular way, but instead be moldable with [the idea] and try different ways of approaching something.

Question 2. How does the social and situated context of extra-curricular start-up programs shape learning processes and learning outcomes?

With respect to question 2, our analysis identifies three interrelated components of the social and situated learning context channeled through the extra-curricular start-up program. Each component plays a central role in shaping processes and outcomes of learning experienced by the students.

\section{Enablers}

The first component in the social and situated learning context of extra-curricular start-up programs refers to enablers. This encompasses activities aimed at creating favorable circumstances for entrepreneurial learning which are managed by the different organizers of the start-up program. These activities often take place in the close vicinities and contexts where each organizer is embedded but they can also take place across the organizations collaborating via the project. The emerging data structure identified four distinct subcategories of enablers: (1) resource provision, (2) expansion of networks, (3) means-driven organizing and (4) supporting community building.

Resource provision refers to the offering of office space and process support such as business coaching to students. It also refers to channeling the students to resources that cannot be provided directly by the organizers, such as lawyers, venture capitalists and financial experts. In these situations, the managers of the start-up program act as intermediaries between students and different resource providers, which is illustrated by one of the students as follows:

... it's sort of pointing towards opportunities that we did not know existed before, also in terms of referring us elsewhere when there was a service they themselves did not provide... you have all 
these lawyers for instance, and accountants that they suggested that we could go and talk to about certain things.

Expansion of networks refers to efforts with the aim to connect students with each other as well as with other people and organizations who not necessarily are part of the start-up program. The creation and maintenance of these social networks opens up opportunities for strengthening relationships which develop their sense of belongingness and encourage them to pursue their entrepreneurial path. This social networking was expressed by a project manager in the following way:

[By participating in the start-up program] “...they will have access to more networks, to more facilities, to more expertise, and also to peer to peer access.

[This is] “. . . giving them an opportunity to actually get to know other start-ups and follow each other for a little while, creating relations."

Means-driven organizing refers to efforts by the program managers to use the resources they have at their disposal while at the same time being flexible in adjusting the program content to the situational needs of the participants. The organizing activities thus become dynamic in nature, largely driven by available means rather than predetermined goals. One project manager informed:

...the content, to begin with. . . were focusing a lot on the product. . . [but] that was a little bit hard to talk generally about, since a lot of our teams had so many different projects, and a lot of them actually were service-oriented. . . So actually, we did not do the product development workshop... Instead, we did a team-building workshop.

Community building refers to the use of language and storytelling as means to integrate the students into entrepreneurial ways of thinking and acting and creating a sense of belongingness based on shared histories, goals and beliefs. The community building efforts in the start-up program centers on the "inner sphere" involving students and project managers and their respective partner institutions but it also connects with a broader "outer sphere" encompassing the entrepreneurial ecosystem surrounding the region. This was described by one of the project managers as follows:

... a part of an entrepreneurial mindset is being part of an ecosystem-a community [where]. . .to collaborate and mingle, and give and get feedback from a lot of different stakeholders. . . that's a thing that the program is manifesting.

Overall, the analysis suggests that these enablers, which are initiated and orchestrated by the project managers, create a platform that provides favorable conditions for an emerging social learning context. It is within this social learning context that the next two components develop throughout the start-up program.

\section{Social learning culture}

The second component in the social and situated learning context of extra-curricular start-up programs refers to social learning culture. This learning culture encompasses the immediate physical and social setting of the program centered on the participants and the people and institutions with whom they interact. Social learning culture was in this context manifested through the emotional and perceptual attributes students associated with the learning environment. Our inductive analysis identifies three distinct sub-categories forming the social learning culture (1) community membership, (2) inspiration and (3) safety and comfort.

Community membership refers to a defined social context where members commit to a set of commonly shared beliefs and behavioral norms. This is characterized by strong feelings of belongingness and a sense of pride connected to being committed to the project. Some
Students' extracurricular startup programs 
IJEBR

28,2

336

students discussed these feelings in terms of social connections to other like-minded people with the opportunity to discuss and share common interests in entrepreneurship. As expressed by one of the students:

... how proud [I am to be part] of the project, and how cool it is to be in an environment where you can talk to other people who have great ideas.

Inspiration refers to the feelings of being mentally stimulated by others with respect to new and creative ideas. This feeling was something that made students comfortable with their own ideas and entrepreneurial intentions. As one student reported:

... it's a great experience to see how other participants work, and learn from them, and bring inspiration back to my own company.

Another student described this inspiration in terms of satisfaction of being part of a creative and innovative atmosphere:

...there is a lot of creative and open-minded people. . . a very innovative and creative environment, and you sort of feel that.

Safety and comfort refer to a social context where members feel accepted and respected. This creates strong feelings of being in a safe and comfortable place and strengthens the willingness to openly share ideas with little fear of negative consequences. One of the project managers described this supportive environment as follows:

... some of them have been very happy about the pitching workshops, .. . being able to present and [at the same time] be in a safe environment. . . becoming a group together with other students and having a network. . ., where they can talk to each other and help each other, and be open to each other.

\section{Learning processes}

The third component in the social and situated learning context of extra-curricular start-up programs refers to learning processes. This component encompasses the social interactions between the participating students, which stimulate growth, development and change. Our inductive analysis identifies two distinct sub-categories of social interactions belonging to this category: (1) communication and observation and (2) peer feedback.

Communication and observation refer to interactions where students actively engage in with each other by exchanging opinions, suggestions, or ideas about their own or others' venturing efforts. It also includes passively observing others' actions. Communication and observation opened up opportunities to explore meaning and understanding in a range of different spaces. One of the student expressed this learning opportunity as follows:

[This is... ] ...because everybody has the same mind-set. So you're learning from the way everybody are doing their things... In a way, you're kind of catching up on the good at every different saga.

The analysis suggests that students communicate with others both spontaneously and informally throughout the various organized activities during the program such as workshops and group work. In this respect, the program creates an organized learning space where students can grow and develop. One student stated the following:

...personally, I've been seeing another guy here trying to do this stuff. I've been learning a lot, actually, from [observing] their idea and their way of doing stuff. So, I think it's a great thing how they organize different groups together.

Peer feedback refers to the interactions where students cooperate with other students via dialogs related to performance and standards. Students were engaged in various forms of 
dialogs such as debates and discussions resulting in peer feedback that allowed them to arrive at explanations which made sense to them. This feedback was valued highly by students and they used it to modify their venture ideas. One student shared the following:

[What I valued most was] . . . the feedback from other participants. . . I think that's what I used most. Some of the feedback was where I sort of changed the way I put my business idea forward depending on what people told me that they liked or did not like in it.

The peer feedback is often perceived as being objective, especially if compared to the feedback received from the closer surroundings such as for example family members and close friends. This was even indicated by some participating students as one of the main reasons for joining the program, which was described as follows:

[It is valuable with] . . somebody who could be critical to the project and ask critical questions to push me. . . because when you tell your family and friends, they're like, 'Yeah, really good and super.' But I needed someone from the outside who... just push [me], and also somebody who knows about business and engineering [issues], because it's also a story by its own...

Question 3. What conditional features impede or facilitate learning processes and learning outcomes in extra-curricular start-up programs?

With respect to question 3, our analysis identifies two main conditional features impeding or facilitating the learning processes and outcomes in extra-curricular start-up programs, which we label participatory conditions. The participatory conditions affect students' motivation to actively engage in the situated learning context and refer to the scope of commitment they partake in the social learning culture, which can be regarded as ranging from peripheral to central. The analysis suggests that participatory conditions indirectly influence the entrepreneurial learning outcomes from the start-up program, where an active participation through a central role in the learning culture is mediated by two conditional features; time allocation and project proximity.

Time allocation. One conditional feature found to affect students' degree of participation in the situated learning context was time allocation, which relates to their commitments and responsibilities outside the extra-curricular start-up program. Balancing study work and active engagement in the extra-curricular start-up program were considered to be difficult for some of the participating students. The difficulties of balancing different demands made these participants struggle with their intentions to participate in the social learning culture. As extra-curricular activities are undertaken on a voluntary basis this can influence the time and energy students set aside to commit to the program. Students that felt they had "too much on their plate" expressed concerns that the limited time available made it hard for them to fully commit to the social learning culture developing in the program. As a coping strategy, they narrowed down their focus and aimed only at participating in what was necessary in order to complete the program. One of the student shared this concern in the following way:

There is something about the time... where to place the courses and the workshops..... . so it has to fit my day.... and [at the same time] people were also struggling with the exams

Another student expressed the following regarding allocated time in the program:

If you want to be in a start-up program like this, you have to be. . I mean, you have to take the time. We did not...

Project proximity. The other conditional feature found to impact students' motivation to actively participate in the situated learning context was project proximity. The analysis suggests that students were more committed to actively engage in the social learning culture
Students' extracurricular startup programs 
IJEBR

28,2

338

if their venture projects were close to other students' projects in the program. Project proximity refers to the degree of closeness of the venture projects that were part of the startup program. Most of the business ideas in the program were at relatively early stages of development. The students who championed more developed business ideas relative to others took a more peripheral role in taking part of the social learning culture, and they were subsequently less actively involved in learning processes. This peripheral role was expressed via perceptions that they would not gain so much from closer interactions with their peers due to the lack of project proximity. One of the students informed:

For our start-up, we were maybe a bit too far [ahead] compared to other teams. For us it was not the most ideal programme because we could not compare [us] with other teams, as we were a bit further than the others.

Another student shared the following concerns regarding project proximity:

I felt like we were maybe a bit further [in our venture idea] than a lot of the other start-ups. . . we had some different questions, which were not always possible to answer [in the group]... people would be like, 'I do not really know this.

To conclude, entering the start-up program with time pressure (real or perceived) as well as bringing a more distant venture project related to the other projects in the program seem to decrease the motivation of participants to actively engage in the social learning culture, thus indirectly influencing entrepreneurial learning outcomes.

\section{A dynamic process view of entrepreneurial learning in extra-curricular start-up programs}

The three building blocks identified in our analysis enable us to build a theoretical structure for the social and situated experiences of students who participate in extra-curricular startup program. From this departure, our analysis has been aimed at developing a processfocused model depicting the dynamic relationships of entrepreneurial learning in extracurricular start-up programs grounded in our data structure. The model is illustrated in Figure 1.

Overall, Figure 1 provides an inductive model of the learning experiences of students in extra-curricular start-up programs. The three components constituting the situated learning context - in the model labeled "Enablers", "Social learning culture" and learning processes' play a key role for mediating and orchestrating entrepreneurial learning dynamics in the start-up program. However, the analysis also suggests a temporal shift in the relative significance of the three components as the program evolves. Enablers are critical at the beginning of the program for igniting the necessary conditions for a social learning culture to emerge. In this respect, enablers are effective in connecting the participants to each other, embedding them in networks, as well as creating favorable conditions for students to engage in entrepreneurial ways of thinking and acting. One of the students described this critical role as follows:

Actually, the first time we were together [the project manager] did an exercise which was about taking action if you need anyone. ... I think everyone found someone who knew someone else that could be used for interviews, or testing, or maybe a potential client or something.

The enablers facilitate communication between students, project managers and other resource providers in the surrounding entrepreneurial ecosystem by providing "bridges" that leverage entrepreneurial talent and resources (e.g. Cordea, 2014). At the same time, the enablers allow students to develop their own initiatives in ways that is most appropriate for them and forming their own personal image as an entrepreneur (Rae, 2006). In this respect, enablers seem to play a critical role early on in the process of developing necessary conditions for entrepreneurial learning, leading to the following proposition: 


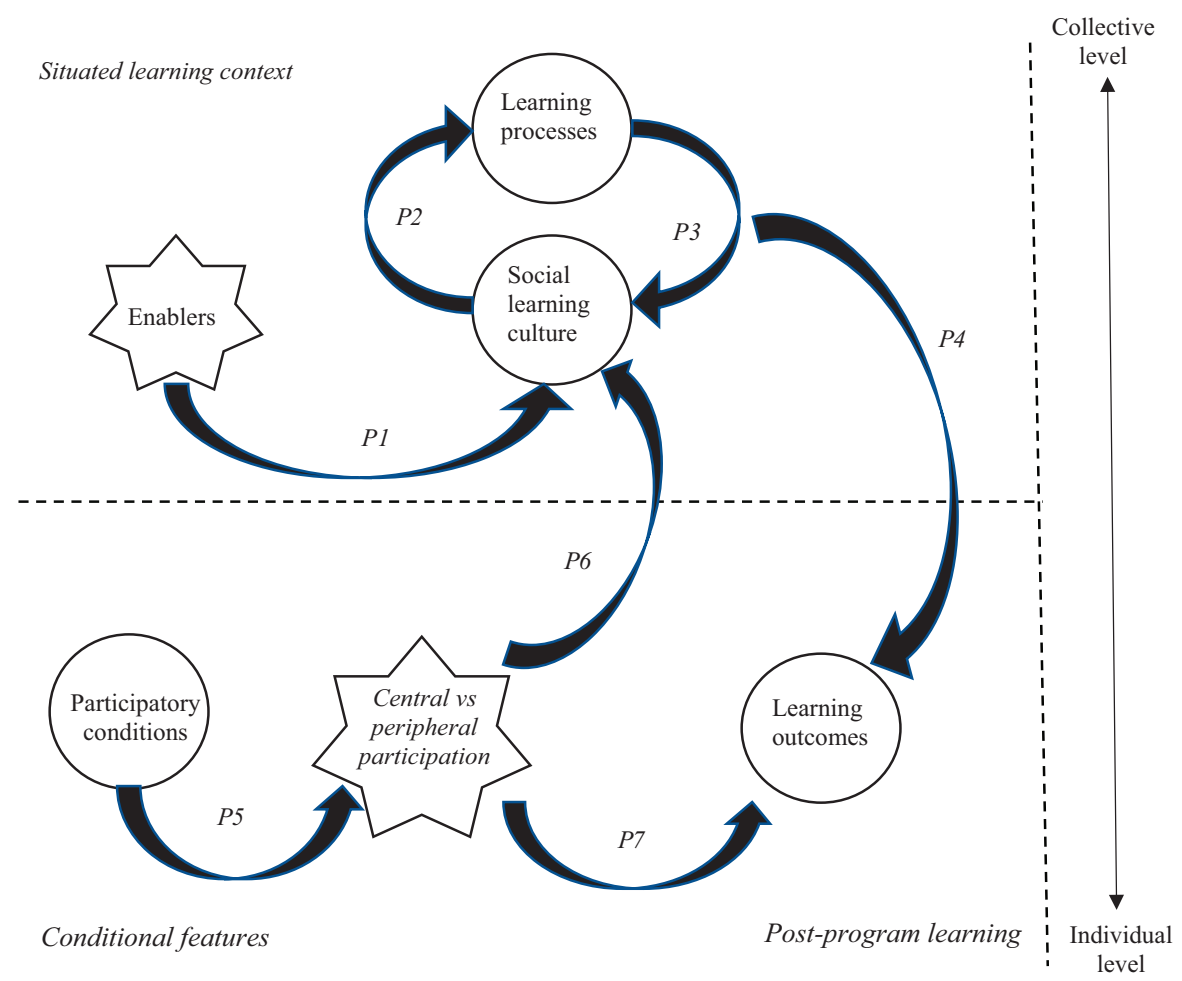

Students' extracurricular startup programs

339

Figure 1.

Processes and outcomes of entrepreneurial learning in extracurricular start-up programs

P1. Enablers play a key role in igniting the necessary conditions for a social learning culture to emerge in extra-curricular start-up programs.

However, our analysis suggest that enablers lose their overall importance over time relative to the other two components portraying the situated learning context when it comes to energizing and orchestrating entrepreneurial learning. Instead, once the start-up program is up and running the major share of learning experiences expressed by the students relate to the "social learning culture" and the "learning processes" that occur reciprocally. These components influence entrepreneurial learning among the students by providing a collective environment where they can learn entrepreneurial behaviors from each other through observation and modeling behavior (Bandura, 1977). This social dimension of entrepreneurial learning was expressed by one of the students as follows:

I think the most valuable [for me] was learning from other start-ups because. . . they could give you step-by-step, so to speak, on how to go about doing something and telling you their experiences.

Overall, the findings corroborate the importance of social and conversational modes of experiential learning that can benefit the venture creation process (Taylor and Thorpe, 2004). Our analysis suggests that the social relationships that emerge in the start-up program stimulate learning and development through access to information (Jack and Anderson, 2002) and the accrued resources assist students in processing learning within situations of uncertainty (Neck and Greene, 2011). The participants may in this respect learn collectively, with their own learning directly affected by the extent to which they are able to coordinate 
IJEBR

28,2

340

their actions by working alongside each other as peers based on shared concerns (e.g. Lave and Wenger, 1991). These learning dynamics lead us to propose the following:

P2. Initial commitments to the social learning culture feed forward into the learning processes via spontaneous and self-initiated interactions among peers.

Our analysis of the situated learning context suggests that the social learning culture that is formed within the start-up program leads to spontaneous and self-initiated interactions via communication and observation, as well as increasing levels of peer feedback. These interactions, in turn, create a positive spiral of escalating engagement influencing the overall learning experience of students. In this respect, initial affective commitments feed forward into the learning processes, which then feed positively back again to strengthen students' affective commitment to the social learning culture. The two components are in close interaction when it comes to providing opportunities to experiment, exchange ideas and gain hands-on practice. The conducive environment for entrepreneurial learning that is created in the start-up program by such interactions simulates a "real" entrepreneurial environment that is not detached from the business world (Gibb, 2002), which in turn favors the development of both venture creation and enterprising competencies. Consequently, we suggest the following two propositions:

P3. Learning process feedback to the social learning culture by strengthening continuous commitments among community members, thus creating a virtuous cycle that affects the learning experience of students.

P4. Commitments to the social learning culture and engagements in learning processes result in learning experiences associated with venture creation competencies and enterprising competencies.

Moreover, the analysis shows that participatory conditions such as time allocation and project proximity influence the motivation of students to actively participate in the situated learning context. In general, less favorable participatory conditions such as time constraints or low project proximity makes students become a more peripheral member in the community which reduce their overall learning experience. However, our analysis also show that some students with a more peripheral role experience significant benefits from their participation in extra-curricular start-up programs. In these cases, learning experiences are not associated with their exposure to the social learning culture and the learning processes that take place in the community. Instead, they are associated with closer contacts with project managers who continue to provide the student with resources and other sort of guidance or assistance on a "one-on-one" basis. In addition, their learning experience are primarily related to the acquisition of venture creation competencies associated with setting up a new project. Moreover, as one of the more peripheral students whose project were less proximate to the others informed:

...the conversations I had with [the project manager] were way more efficient for me, and much more meaningful... [he] has the right experience to guide me in my business.

Overall, the findings emphasize the importance of understanding different groups of students in relation to their participatory conditions. Students with favorable participatory conditions take a more central role in the social learning culture, thus contributing to the dynamics resulting from interactions between the social learning culture and the learning processes. Students with less favorable participatory conditions take a more peripheral role in the social learning culture and thereby continue to be largely dependent on closer contacts with project managers for their overall learning experience. The above discussion lead us to suggest the following three propositions: 
P5. Time allocation and project proximity are participatory conditions that determine whether students take a central or more peripheral role in the social learning culture.

P6. Students with favorable participatory conditions take a more central role in the social learning culture, and they contribute positively to the learning dynamics characterizing the situated learning context.

P7. Students with less favorable participatory conditions take a more peripheral role in the social learning culture which results in higher dependence on project managers for their learning experience and with learning outcomes primarily associated with venture creation competencies.

\section{Conclusions and implications}

There is a worldwide interest in connecting students with academic research and supporting infrastructures as means to foster and promote entrepreneurship and innovation (Pittaway et al., 2020). In this paper, we have focused our attention on university-led extra-curricular start-up programs with the overall purpose to explore the social and situated experiences of students who participate in such programs, as well as how the processes and outcomes of entrepreneurial learning are potentially shaped by this particular context. Empirically, we have followed four rounds of extra-curricular start-up programs offered to students in three universities located in Greater Copenhagen.

Overall, our findings suggest that extra-curricular start-up programs can serve as effective means to strengthen the entrepreneurial intentions and behaviors of students at higher educational institutions. The inductive analysis identifies two main learning outcomes experienced by the students after completion of the start-up program. The first learning outcome, venture creation competencies, is related to the ability of students to build legitimacy and capabilities to cope with liabilities of newness in early stages of new venture creation. The other learning outcome, enterprising competencies, is related to the ability of students to develop awareness about entrepreneurial values and beliefs and internalizing and incorporating socially held behavioral expectations about their role as enterprising individuals in a surrounding ecosystem. Both learning outcomes are perceived as useful by students for expanding their knowledge structures and developing greater self-confidence in performing entrepreneurship.

Moreover, the analysis identifies three interconnected components in the situated context of start-up programs that trigger learning dynamics. We find that the components vary in their relative importance as drivers of entrepreneurial learning over the course of the start-up program. Enablers, which are in the hands of project managers, are important for building a social learning culture and energizing learning processes in the beginning of the start-up program. Once these enablers are in place they collectively create a virtuous, self-sustaining community that acts as a vehicle for social learning supporting student entrepreneurship. Thus, our findings emphasize the importance of including temporal dimensions in theoretical models aimed at understanding the social and situated learning experience of students participating in extra-curricular start-up programs.

Furthermore, the findings emphasize the importance of acknowledging the varying needs of different groups of students in relation to their participatory conditions. Most students are able to actively engage in the situated learning context of start-up programs where the learning dynamics become largely self-sustaining and driven by continuous interactions and feedback among peers. However, a few students who enter start-up programs have less favorable participatory conditions which result in them taking a more peripheral role in the social learning culture. The learning experience of these students relies heavily on closer contacts with individual project managers and with learning outcomes primarily associated with venture creation competencies.
Students' extracurricular startup programs 
IJEBR

28,2

\section{2}

\section{Contributions}

Our study offers two primary contributions to research. First, we extend entrepreneurial learning theory by developing a grounded process-focused model that connects individual and collective levels of learning. Past research has largely focused on psychological and cognitive processes that drive the entrepreneurial learning process while neglecting the interface between the individual and the social context where this learning occurs (Wang and Chugh, 2014). In this respect, our findings elucidate how individual learning experiences are potentially shaped by the immersion, comprehension and co-participation in entrepreneurship as social practice (Taylor and Thorpe, 2004), which enable students to expand knowledge structures and develop greater self-confidence in performing entrepreneurship.

Second, our study adds to theory and research on entrepreneurship education organized by universities outside the formal curriculum. The inductive analysis recognizes extracurricular start-up programs as sites of practice-based knowledge where students are exposed to the entrepreneurial "way of life" (Gibb, 2002). Moreover, we identify how important learning processes are triggered and channeled through interpersonal interactions embedded in social relationships. In this respect, the findings offer unique insights into how the social and relational environment influence and shape the learning experience of students, hence filling the research void on entrepreneurial learning in the situated context of extracurricular education (Preedy and Jones, 2015).

In addition, our study offers contribution to practice. Entrepreneurship education offered at universities has received criticism targeting the orientation of the teaching, where it too often emphasizes the cognitive dimensions of the learning process by focusing on education about entrepreneurship (Arranz et al., 2017). In contrast, our findings suggest that entrepreneurial learning in many ways is an integral and inseparable process of social practice. In this respect, entrepreneurship educators should seek to provide a favorable learning context where students can develop their identities as learners by engaging in processes of participation and interaction through social learning. Offering extra-curricular activities on top of entrepreneurship education courses and programs may in this respect energize the entrepreneurship education curriculum by exposing students to sites of practicebased knowledge where they can apply theory and content learned in the classroom.

\section{Limitations}

Our study is not without limitations. It is generally acknowledged that different national cultures and institutional frameworks evoke different attitudes toward entrepreneurship where some may engender more entrepreneurial behavior than others (Hayton and Cholakova, 2012). The entrepreneurial ecosystem of Greater Copenhagen has a welldeveloped innovation support system that strongly encourages and assists entrepreneurship and innovative ideas originating from universities (e.g. Gabrielsson et al., 2019; Politis et al., 2019). Moreover, the entrepreneurial ecosystem is embedded in Nordic norms and values that typically emphasize egalitarianism, hard work, mutual respect and trust. Therefore, extrapolations to other empirical settings should be considered with care, and we propose critical and context-sensitive examinations of our theory and findings across national cultures and institutional frameworks.

\section{References}

Ardichvili, A. (2003), "Constructing socially situated learning experiences in human resource development: an activity theory perspective", Human Resource Development International, Vol. 6 No. 1, pp. 5-20. 
Arranz, N., Ubierna, F., Arroyabe, M.F., Perez, C. and Arroyabe, J.C.F. (2017), "The effect of curricular and extracurricular activities on university students' entrepreneurial intention and competencies", Studies in Higher Education, Vol. 42 No. 11, pp. 1979-2008.

Åstebro, T.B., Bazzazian, N. and Braguinsky, S. (2012), "Startups by recent university graduates and their faculty - implications for university entrepreneurship policy”, Research Policy, Vol. 41 No. 4, pp. 663-677.

Bandura, A. (1977), "Self-efficacy: toward a unifying theory of behavioural change", Psychological Review, Vol. 84 No. 2, pp. 191-215.

Cope, J. (2005), "Toward a dynamic learning perspective of entrepreneurship", Entrepreneurship: Theory and Practice, Vol. 29 No. 4, pp. 373-389.

Cordea, C. (2014), "The role of extracurricular activities and their impact on learning process", Annals of Faculty of Economics, Vol. 1 No. 1, pp. 1143-1148.

Fetters, M., Greene, P. and Rice, M.P. (2010), The Development of University-Based Entrepreneurship Ecosystems, Edward Elgar, Cheltenham.

Foss, L. and Gibson, D.V. (2015), The Entrepreneurial University: Context and Institutional Change, Routledge, New York, NY.

Gabrielsson, J., Politis, D. and Billström, A. (2019), "University spin-offs and triple helix dynamics in regional innovation ecosystems: a comparison of technology intensive start-ups in Sweden", Global Business and Economics Review, Vol. 21 Nos 3/4, pp. 362-381.

Gibb, A. (2002), "Creating conductive environments for learning and entrepreneurship", Industry and Higher Education, Vol. 16 No. 3, pp. 135-138.

Gioia, D.A., Corley, K.G. and Hamilton, A.L. (2012), "Seeking qualitative rigor in inductive research. Notes on the Gioia methodology", Organizational Research Methods, Vol. 16 No. 1, pp. 15-31.

Hägg, G. and Gabrielsson, J. (2020), "A systematic literature review of the evolution of pedagogy in entrepreneurial education research", International Journal of Entrepreneurial Behavior and Research, Vol. 3 No. 2, pp. 129-153.

Hayton, J.C. and Cholakova, M. (2012), "The role of affect in the creation and intentional pursuit of entrepreneurial ideas", Entrepreneurship: Theory and Practice, Vol. 36 No. 1, pp. 41-68.

Howort, C., Smith, S.M. and Parkinson, C. (2012), "Social learning and social entrepreneurship education", The Academy of Management Learning and Education, Vol. 11 No. 3, pp. 371-389.

Jack, S.L. and Anderson, A.R. (2002), "The effects of embeddedness on the entrepreneurial process", Journal of Business Venturing, Vol. 17 No. 5, pp. 467-487.

Jehn, K.J.K. (2009), "Using triangulation to validate themes in qualitative studies", Qualitative Research in Organizations and Management: An International Journal, Vol. 4 No. 2, pp. 123-150.

Jones, C., Macpherson, A., Thorpe, R. and Ghecham, A. (2007), "The evolution of business knowledge in SMEs: conceptualizing strategic space”, Strategic Change, Vol. 16 No. 6, pp. 281-294.

Jones, C., Matlay, H., Penaluna, K. and Penaluna, A. (2014a), "Claiming the future of enterprise education”, Education + Training, Vol. 56 Nos 8/9, pp. 764-775.

Jones, K., Sambrook, S.A., Pittaway, L., Henley, A. and Norbury, H. (2014b), “Action learning: how learning transfers from entrepreneurs to small firms", Action Learning: Research and Practice, Vol. 11 No. 2, pp. 131-166.

Kolympiris, C. and Klein, P.G. (2017), "The effects of academic incubators on university innovation", Strategic Entrepreneurship Journal, Vol. 11 No. 2, pp. 145-170.

Kubberød, E. and Pettersen, I. (2017), "The role of periherality in students' entrepreneurial learning", Education + Training, Vol. 60 No. 1, pp. 2-15.

Kwong, C.C.Y., Thompson, P., Cheung, C.W.-M. and Manzoor, H. (2012), "The role of environment in fostering conductive entrepreneurial learning”, Journal of General Management, Vol. 38 No. 1, pp. $45-71$. 
IJEBR

28,2

344

Lave, J. and Wenger, E. (1991), Situated Learning, Legitimate Peripheral Participation, Cambridge University Press, Cambridge.

Levinsohn, D.S. (2015), "No entrepreneur is an Island: an exploration of social entrepreneurial learning in accelerators", Dissertation Series, No. 105, Jönköping International Business School (JIBS).

Lindholm Dahlstrand, A. and Berggren, E. (2010), "Linking innovation and entrepreneurship in higher education: a study of Swedish schools of entrepreneurship", in Oakey, R., Groen, A., Cook, G. and Van der Sijde, P. (Eds), New Technology-Based Firms in the New Millennium, Emerald Group Publishing, Bingley, Vol. 8, pp. 35-50.

McGee, J.E., Peterson, M., Mueller, S.L. and Sequeira, J.M. (2009), "Entrepreneurial self-efficacy: refining the measure", Entrepreneurship: Theory and Practice, Vol. 33 No. 4, pp. 965-988.

Morris, M.H., Shirokova, G. and Tsukanova, T. (2017), "Student entrepreneurship and the university ecosystem: a multi-country empirical exploration", European Journal of International Management, Vol. 11 No. 1, pp. 65-85.

Neck, H.M. and Greene, P.G. (2011), "entrepreneurship education: known worlds and new Frontiers", Journal of Small Business Management, Vol. 49 No. 1, pp. 55-70.

Newman, A., Obschonka, M., Schwarz, S. and Cohen, M. (2019), "Entrepreneurial self-efficacy: a systematic review of the literature and its theoretical foundations, measurement, antecedent, and outcomes, and an agenda for future research", Journal of Vocational Behavior, Vol. 110, pp. 403-419.

Penaluna, K., Penaluna, A. and Jones, C. (2012), "The context of enterprise education: insights into current practices", Industry and Higher Education, Vol. 26 No. 3, pp. 1-13.

Pittaway, L. and Cope, J. (2007), "Simulating entrepreneurial learning: integrating experiential and collaborative approaches”, Management Learning, Vol. 38 No. 2, pp. 211-233.

Pittaway, L.A., Rodriguez-Falcon, E.M., Aiveghavo, O. and King, A. (2010), "The role of entrepreneurship clubs and societies in entrepreneurial learning”, International Small Business Journal, Vol. 29 No. 1, pp. 37-57.

Pittaway, L.A., Gazzard, J., Shore, A. and Williamson, T. (2015), "Student clubs: experiences in entrepreneurial learning”, Entrepreneurship and Regional Development, Vol. 27 Nos 3/4, pp. 127-153.

Pittaway, L., Aissaoui, R., Ferrier, M. and Mass, P. (2020), "University spaces for entrepreneurship: a process model”, International Journal of Entrepreneurial Behavior and Research, Vol. 26 No. 5, pp. 911-936.

Politis, D., Gabrielsson, J., Galan, N. and Akele Abebe, S. (2019), "Entrepreneurial learning in venture acceleration programs", The Learning Organization, Vol. 26 No. 6, pp. 588-603.

Politis, D. (2005), "The process of entrepreneurial learning: a conceptual framework", Entrepreneurship: Theory and Practice, Vol. 29 No. 4, pp. 399-422.

Preedy, S. and Jones, P. (2015), "An investigation into university extra-curricular enterprise support provision”, Education + Training, Vol. 57 Nos 8/9, pp. 992-1008.

Preedy, S., Jones, P., Maas, G. and Duckett, H. (2020), "Examining the perceived value of extracurricular enterprise activities in relation to entrepreneurial learning processes", Journal of Small Business and Enterprise Development, Vol. 27 No. 7, pp. 1085-1105.

Rae, D., Martin, L., Antcliff, V. and Hannon, P. (2012), "Enterprise and entrepreneurship in English higher education: 2010 and beyond", Journal of Small Business and Enterprise Development, Vol. 19 No. 3, pp. 380-401.

Rae, D. (2002), "Entrepreneurial emergence: a narrative study of entrepreneutrial learning in independtly owned media businesses", International Journal of Entrepreneuship and Innovation, Vol. 3 No. 1, pp. 53-59.

Rae, D. (2006), "Entrepreneurial learning: a conceptual framework for technology-based enterprise", Technology Analysis and Strategic Management, Vol. 18 No. 1, pp. 39-56.

Shirokova, G., Osiyevskyy, O., Morris, M. and Bogatyreva, K. (2017), "Expertise, university infrastructure and approaches to new venture creation: assessing students who start businesses”, Entrepreneurship and Regional Development, Vol. 29 No. 9, pp. 912-944. 
Spagnoli, P., Santos, S.C. and Caetano, A. (2017), "A contribution toward the adaptation and validation of the entrepreneurial self-efficacy scale in Italy and Portugal”, Journal of Career Assessment, Vol. 25 No. 4, pp. 670-687.

Spigel, B. (2017), "The relational organization of entrepreneurial ecosystems", Entrepreneurship: Theory and Practice, Vol. 41 No. 1, pp. 49-72.

Taylor, D.W. and Thorpe, R. (2004), "Entrepreneurial learning: a process of co-participation”, Journal of Small Business and Enterprise Development, Vol. 11 No. 2, pp. 203-211.

Thomassen, M., Williams Middleton, K., Ramsgaard, M., Neergaard, H. and Warren, L. (2019), "Conceptualizing context in entrepreneurship education: a literature review", International Journal of Entrepreneurial Behavior and Research, Vol. 26 No. 5, pp. 817-828.

Vanevenhoven, J. and Drago, W.A. (2015), "The structure and scope of entrepreneurship programs in higher education around the world", in Rae, D. and Wang, C.L. (Eds), Entrepreneurial Learning: New Perspectives in Research, Education and Practice, Routledge, New York, pp. 117-133.

Vygotsky, L.S. (1978), Mind in Group: The Development of Higher Education Psychological Processes, Harvard University Press, Massachusetts.

Wang, C.L. and Chugh, H. (2014), "Entrepreneurial learning: past research and future challenges", International Journal of Management Reviews, Vol. 16 No. 4, pp. 24-61.

Welter, F. and Gartner, B. (2019), A Research Agenda for Entrepreneurship and Context, Edward Elgar, Cheltenham.

Wenger, E. (1998), Communities of Practice: Learning, Meaning and Identity, Cambridge University Press, Cambridge.

Williams Middleton, K., Padilla-Meléndez, A., Lockett, N., Quesada-Pallarès, C. and Jack, S. (2019), "The university as an entrepreneurial learning space: the role of socialized learning in developing entrepreneurial competence", International Journal of Entrepreneurial Behavior and Research, Vol. 26 No. 5, pp. 887-909.

Wright, M. and Drori, I. (2018), Accelerators, Edward Elgar publishing, Chelthenham.

Youtie, J. and Shapira, P. (2008), "Building an innovation hub: a case study of the transformation of university roles in regional technological and economic development", Research Policy, Vol. 37 No. 8, pp. 1188-1204.

Yusef, S. (2008), "Intermediating knowledge exchange between universities and businesses", Research Policy, Vol. 37 No. 8, pp. 1167-1174.

\section{Corresponding author}

Jasna Pocek can be contacted at: jasna.pocek@fek.lu.se

For instructions on how to order reprints of this article, please visit our website:

www.emeraldgrouppublishing.com/licensing/reprints.htm

Or contact us for further details: permissions@emeraldinsight.com 